\title{
Diversity of Volatile Organic Compounds in leaves of Pimenta dioica L. Merrill at Different Developmental Stages from Fruiting and no-fruiting Trees
}

\author{
Isis Montalvo-Lopez ${ }^{1 *}$, Domingo Montalvo-Hernández ${ }^{2}$, Jorge Molina-Torres ${ }^{1}$ \\ ${ }^{1}$ Laboratorio de Fitobioquímica. CINVESTAV, U. Irapuato. Km 9.6 Libramiento Norte. Carretera Irapuato- \\ León, Código Postal 36824, Irapuato, Guanajuato, México. \\ ${ }^{2}$ Departamento de Fitotecnia. Universidad Autónoma Chapingo. Carretera México-Texcoco km 38.5, Código \\ Postal 56230, Chapingo, Estado de México, México.
}

*Corresponding author: I. Montalvo-Lopez, e-mail: montalvo0227@gmail.com

Received January $11^{\text {th }}, 2021$; Accepted May $5^{\text {th }}, 2021$.

DOI: http://dx.doi.org/10.29356/jmcs.v65i3.1498

\begin{abstract}
Pimenta dioica L. Merrill, known as pimienta gorda, xocoxochitl (in Nahuatl) or allspice, is native to Mesoamerica. In Mexico, it has been used since pre-Hispanic times due to its medicinal properties and as a condiment for the preparation of "tamales" and "moles". The dried fruits have a high economic value due to their flavor and aroma: a combination of cinnamon, nutmeg and clove. For this reason, it is known as allspice in English. Xocoxochitl is a dioecious tree. The fruiting, female trees, have a greater economic importance, while non-fruiting trees, or male trees, function to some extent as pollinators. However, leaves and fruits present similar volatile organic compounds (VOCs) responsible for the already mentioned properties. In order to evaluate the VOCs in leaves at different developmental stages, leaves were collected from: 2-years-old sexually undifferentiated trees and 14-years-old female and male differentiated trees. VOCs were collected and evaluated using SPME-GC-MS. Data obtained show a great diversity of VOCs at all leaf developmental stages, regardless of the tree analyzed. The dried fruit essential oil is highly valued by the international industry, but the leaves have minor use. However, leaves showed a great VOCs richness containing most of the dried fruit compounds. The VOCs profile in female and male trees were also evaluated. Individual VOCs displayed a different relative amount in each leaf developmental stage, as well as specific compounds for each type of tree were identified.
\end{abstract}

Keywords: VOCs; allspice; SPME; terpenes.

Resumen. Pimenta dioica L. Merrill, conocida como pimienta gorda, xocoxochitl (en náhuatl) o como allspice, es originaria de Mesoamérica. En México, se ha usado desde la época prehispánica debido a sus propiedades medicinales, así como condimento para la preparación de tamales y moles. Los frutos secos tienen un alto valor económico debido a su sabor y aroma: una combinación de canela, nuez moscada y clavo. Por esta razón, en inglés se le llama allspice. Xocoxochitl es un árbol dioico. Los árboles que fructifican, árboles hembra, presentan una mayor importancia económica mientras que los árboles que no fructifican, árboles macho, funcionan en forma limitada como polinizadores. Sin embargo, las hojas y los frutos presentan compuestos orgánicos volátiles (COVs) similares responsables de las características mencionadas. Con el fin de evaluar los COVs presentes en hojas de diferentes estados de desarrollo, se colectaron hojas de árboles no diferenciados de 2 años de edad, así como de árboles diferenciados, hembra y macho, de 14 años de edad. Los COVs fueron colectados y analizados mediante SPME-GC-MS. Los datos obtenidos muestran una riqueza de COVs en todos los estados de desarrollo de la hoja, independientemente del árbol analizado. El aceite esencial del fruto seco es 
altamente apreciado en la industria internacional, sin embargo, las hojas presentan un menor uso. Además, también se evaluó el perfil de COVs de árboles hembra y macho. Ciertos COVs mostraron una cantidad relativa diferente en cada estado de desarrollo de la hoja, así mismo, se identificaron compuestos específicos para cada tipo de árbol.

Palabras clave: COVs; pimienta gorda; SPME; terpenos.

\section{Introduction}

Pimenta dioica L. Merrill (Myrtaceae) is a perennial tree native to Mexico and Central America traditionally named Xocoxochitl (from Nahuatl). Nowadays it is known as "Pimienta de Tabasco" or "Pimienta Gorda" due to the fruit morphology [1]. Currently Jamaica is the largest producer of this spice thus eventually named Jamaica pepper. Xocoxochitl is also named as allspice due to the aroma and flavor of its fruits: a combination of nutmeg, clove, cinnamon, and black pepper [2]. The main demand of the extracted essential oil is to satisfy the perfumery industry. Leaves are locally used only in a small scale for flavoring food and traditional medicine [2].

P. dioica is a dioecious species: the flowers present sexual dimorphism. They are structurally hermaphrodites but functionally dioecious $[3,4,5]$. This means that the trees have complete flowers but with specific characteristics for female or male trees (Fig. 1). Female flowers have about 30 stamens and the pistil is larger than the stamens (Fig. 1 (a), (b)). The fruiting trees are the female, for this reason considered more important. On the other hand, male flowers have around 80 stamens, the pistil is shorter and covered by the stamens. These flowers are not fertile (Fig. 1 (c), (d)). Tree differentiation can be achieved only after five years of age, when the first flowering and fructification occurs. Observations in Jamaica indicate that male trees rarely produce fruits, these containing only one seed [3], nonetheless our observations in the harvest period, fruits from female trees have 1 to 4 seeds and male trees do not produce any fruits. To date, there is not protocol to distinguish the tree sex before the flowering. It is worth to mention that all flowers produce pollen regardless the tree type, so the female tree can pollinate by itself. In this way, male trees are just strictly necessary on field to assurance an effective pollination. For the above, the male trees probably are not needed in a fruit production system.

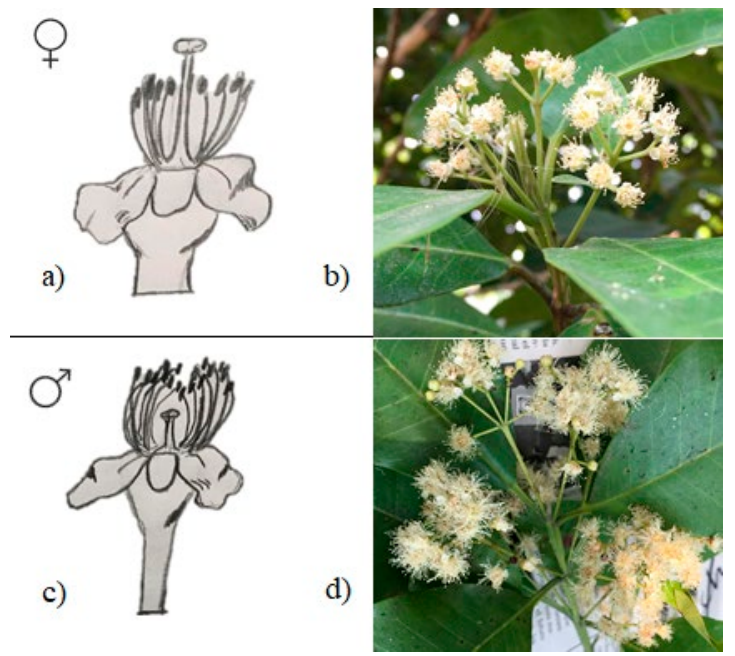

Fig. 1. Flowering of Pimenta dioica. (a) Female open flower (anthesis), (b) female inflorescence, (c) male open flower (anthesis) and (d) male inflorescence. 
Allspice fruits are worldwide used for different purposes. Nevertheless, in the Totonacapan region, state of Veracruz, Mexico, the leaves are used instead. Some traditional Meso American corn dishes are prepared with a special sauce of chilis and $P$. dioica leaves. Also, leaf infusions are used to calm abdominal pains. Studies related to the composition of $P$. dioica leaf oil reported about 30 compounds depending on the extraction method and analytical tools. The techniques to obtain the oil involving high temperatures can alter the final composition since most volatile compounds can be lost.

The crushed fresh leaf aroma evidences the diversity of compounds contained in this tissue. Even when the leaf completes its life cycle, falls down on the soil and gets dry, it keeps its aroma. The aim of this study is to evaluate the VOCs profile in leaves of Pimenta dioica at different developmental stages from either 2-yearsold undifferentiated trees, as well as fruiting and no-fruiting trees to provide information about the richness of compounds in leaves.

From the above, it is interesting to study the VOCs present in P. dioica leaves using Solid Phase Micro Extraction (SPME) technique and determined with Gas Chromatography coupled to Mass Spectrometry (GC/MS) since it is a fast, solvent free and highly reproducible technique. With this method, it is possible to obtain a better overview of the VOCs richness in leaves. The published information about $P$. dioica leaves lack important information about leaves development, tree phenology and the type of tree, female or male. In this study, the VOCs profile of leaves from either young undifferentiating trees, female and male trees was examined to calculate the relative concentration of VOCs using SPME-GC/MS. Also, three different stages of development: young, medium and mature were compared. This is the first report of VOCs profile from allspice leaves using SPME-GC-MS where 90 compounds were detected. The data show the richness of VOCs at all the development stages regardless the type of tree. Although the essential oil from dried fruits is appreciated for its richness in aroma and flavors industry, leaves as such, have a potential to offer a valuable essential oil product.

\section{Experimental}

\section{Plant material}

Leaves from three different developmental stages: young, medium and mature were analyzed. These can be distinguished by the leaf size and color mostly related to the chlorophyll content (Fig. 2). The leaves were collected from the medium part of the tree canopy, they were cut individually and kept in bags to maintain their humidity in a cooler box. Leaves were collected in October 2018, when the trees were in their fruit ripening season. From differentiating trees, leaves were collected from three female and three male trees in the community of Tilzapota, Atzalan, state of Veracruz, Mexico from a commercial production grove $\left(19^{\circ} 53^{\prime} 11^{\prime \prime} \mathrm{N}, 97^{\circ} 10^{\prime} 57^{\prime \prime} \mathrm{W}, 627 \mathrm{~m}\right.$ above sea level). These trees were 14-years-old and were propagated from seeds. Leaves from three 2-years-old sexually undifferentiated plants were also collected. These plants were propagated from seeds obtained from "La Garita" nursery in Tlapacoyan, Veracruz, Mexico and then cultivated in Tilzapota, Veracruz, from which leaves were collected.



Fig. 2. Developmental stages of leaves from Pimenta dioica: i) young leaf; ii) medium leaf and iii) mature leaf. Scale bar: $2 \mathrm{~cm}$. 


\section{Experimental analysis}

Leaves were washed with distillated water and weighted individually, then were chopped and placed into a $50 \mathrm{~mL}$ Erlenmeyer flask sealed with an aluminum cap maintaining the flask at $24{ }^{\circ} \mathrm{C}$ room temperature. The SPME fiber $(50 / 30 \mu \mathrm{m}$ DVB/CAR/PDMS; SUPELCO, Sigma Aldrich, Bellefonte, PA, USA) was previously conditioned and activated at the $\mathrm{GC}$ injection port for $15 \mathrm{~min}$ at $230{ }^{\circ} \mathrm{C}$ and maintained in a desiccator. The fiber was exposed for five minutes at room temperature to the flask head space containing the leaves sample. The exposed SPME was placed into the liner in the injector chamber of the GC and the oven run program started. After $15 \mathrm{~min}$ the clean and reactivated fiber was retracted from the injector and kept it in a desiccator.

\section{Analytical procedure}

The samples were analyzed in an Agilent Gas Chromatography 7890A (Agilent Technologies, EUA) with an HP5MS30M column ( $30 \times 0.25 \times 0.25$; Agilent Technologies, EUA) coupled to an electron impact ionization quadrupole mass analyzer mass spectrometer Hewlett Packard 5975C (Hewlett Packard, EUA). The initial temperature of the oven was of $60^{\circ} \mathrm{C}$ for $1 \mathrm{~min}$ and increased to $280{ }^{\circ} \mathrm{C}$ at $8{ }^{\circ} \mathrm{C} / \mathrm{min}$. The temperature injector was of $230^{\circ} \mathrm{C}$, the ionization source of $230^{\circ} \mathrm{C}$ and the quadrupole of $150^{\circ} \mathrm{C}$. Helium was used as the carrier gas at a $1 \mathrm{~mL} / \mathrm{min}$ constant flow. The identification of VOCs was based in the analysis of the data produced by the GC-EIMS system (Total Ion Chromatograms) collected with the Mass Hunter Workstation software version B.08.00 (Agilent Technologies, Inc.) and then were analyzed with the software Automated Mass Spectral Deconvolution and Identification System (AMDIS v 2.71) to subtract the mass spectrum for each compound from the background. The mass spectra of the possible compounds were compared with the NIST mass spectral library (v 2.0). The relative amount of the compounds from each sample was obtained by dividing the area of the component by the fresh weight of the sample. In this way, the relative amount of the compounds is listed in Table 1 as percent values of the relative amount per $\mathrm{mg}$ of fresh foliar tissue: $\mathrm{mg}[\mathrm{FW}]^{-1}$

\section{Statistical analysis}

Statistical analysis was performed using the bioinformatic program R Studio (3.5.3 version). The significative differences were determined with the one-way ANOVA and the Tukey HSD test. A multivariate analysis was performed using MetaboAnalyst 4.0 (https://www.metaboanalyst.ca).

\section{Results and discussion}

A total of ninety compounds were detected among the samples. From these 90 compounds, fifty-five were identified and analyzed in this study since they were present in all the repetitions (Table 1). The compounds analyzed belong to oxylipins, monoterpenes hydrocarbons and oxygenated, sesquiterpenes hydrocarbons, amino acids derivate and phenylpropanoids. Sesquiterpene hydrocarbons were the group with most compounds giving twenty-five total. Identified compounds and their relative abundance at different developmental stage of leaves from undifferentiated plants, female and male trees as well are listed in Table 1. It was possible to obtain and identify more compounds using SPME-GC-MS compared to distillation techniques. Bajer et al. [6] used this technique to analyze VOCs from allspice dried fruits. They identified 50 compounds using a similar SPME fiber $(50 / 30 \mathrm{~mm}$ DVB/CAR/PDMS). It is important to note that the number of compounds identified from dried fruits and fresh leaves are similar, nonetheless certain compounds were identified at both kind of organs.

The SPME-GC-MS analysis of the VOCs in leaves from two-years-old trees revealed the identification of 49 compounds. $\alpha$-Pinene, $\beta$-pinene, $\beta$-linalool, terpinen-4-ol, $\alpha$-terpineol, eucalyptol, $\alpha$-cubebene, copaene, $\beta$-caryophyllene, $\alpha$-caryophyllene, $\alpha$-selinene, $\beta$-selinene and eugenol showed an increase during leaf development. Only eucalyptol and $\alpha$-terpineol showed a significative difference regarding their relative abundance at different leaf ages $(P<0.01)$ since the mature leaves showed two-fold abundance compared to young and medium leaves. These compounds are connected during the monoterpene synthesis since $\alpha$-terpineol 
is the precursor of eucalyptol, thus probably being the reason for a possible correlation of their abundance in the leaf.

Six compounds were identified exclusively in 2-years-old trees. 1-Butanol 2-methyl-acetate was the only derivate from amino acid biosynthesis which is frequently found in different fruits such banana and apple. $\beta$-Myrcene and D-limonene are monoterpenes characteristic from citric fruits; as a result, the young plants and young leaves have a fresh and soft aroma similar to lemon. 3-Hexen-1-ol, cis-4-decenal and decanal were identified only in these young trees. These compounds are oxylipins with action against herbivory. In fact, 2years-old trees appear to be more susceptible to herbivory because they have a height of $90 \mathrm{~cm}$ and their matures leaves are less coriaceous and with less chlorophyll than the mature leaves of differentiated trees. This could be the reason for the presence of more oxylipin compounds as a defense mechanism in younger trees.

Table 1. Mean relative abundance (area \%) of compounds identified in Pimenta dioica leaves from different developmental stages from 2-years-old trees, as well as female and male trees of 14-years-old $(n=3)$.

\begin{tabular}{|c|c|c|c|c|c|c|c|c|c|c|}
\hline \multirow{2}{*}{ RT } & \multirow{2}{*}{ Compound } & \multicolumn{3}{|c|}{ 2-years-old tree } & \multicolumn{3}{|c|}{ Female tree } & \multicolumn{3}{|c|}{ Male tree } \\
\hline & & $\begin{array}{c}\text { Young } \\
\text { leaf }\end{array}$ & $\begin{array}{c}\text { Medium } \\
\text { leaf }\end{array}$ & $\begin{array}{c}\text { Mature } \\
\text { leaf }\end{array}$ & $\begin{array}{c}\text { Young } \\
\text { leaf }\end{array}$ & $\begin{array}{c}\text { Medium } \\
\text { leaf }\end{array}$ & $\begin{array}{c}\text { Mature } \\
\text { leaf }\end{array}$ & $\begin{array}{c}\text { Young } \\
\text { leaf }\end{array}$ & $\begin{array}{c}\text { Medium } \\
\text { leaf }\end{array}$ & $\begin{array}{c}\text { Mature } \\
\text { leaf }\end{array}$ \\
\hline 2.96 & 3-Hexenal & 0.72 & 3.91 & 3.14 & - & 4.80 & 11.45 & 2.76 & 10.59 & 10.61 \\
\hline 2.98 & 2-Methyl-4-pentenal & - & - & - & 1.44 & - & - & - & - & - \\
\hline 3.59 & trans-2-Hexenal & 0.03 & 0.04 & 0.01 & 0.04 & 0.24 & 0.34 & 0.11 & 0.41 & 0.39 \\
\hline 3.65 & cis-2-Hexenal & - & 0.23 & 0.20 & - & - & 0.15 & - & 0.03 & 0.10 \\
\hline 3.94 & 1-Butanol, 2-methyl-, acetate & 0.15 & - & - & - & - & - & - & - & - \\
\hline 4.03 & 3-Hexen-1-ol & 0.02 & - & - & - & - & - & - & - & - \\
\hline 4.47 & $\beta$-Thujene & 0.36 & 0.09 & 0.11 & 0.48 & 0.45 & - & 0.30 & 0.35 & 0.08 \\
\hline 4.60 & $\alpha$-Pinene & 0.24 & 0.12 & 0.19 & 0.26 & 0.32 & 0.45 & 0.21 & 0.36 & 0.41 \\
\hline 5.22 & Sabinene & 2.44 & 0.51 & 0.46 & 1.72 & 2.66 & - & 2.16 & 3.24 & 0.69 \\
\hline 5.54 & $\beta$-Pinene & 19.93 & 20.04 & 22.14 & 24.58 & 17.65 & 17.49 & 18.14 & 21.56 & 22.97 \\
\hline 5.72 & $\beta$-Myrcene & - & - & 1.35 & - & - & - & - & - & - \\
\hline 5.94 & 2-carene & - & - & - & - & 0.48 & - & - & - & - \\
\hline 5.94 & $\alpha$-Terpinene & 0.54 & - & 0.28 & 0.48 & - & - & 0.18 & 0.33 & 0.46 \\
\hline 6.16 & D-Limonene & - & 4.28 & - & - & - & - & - & - & - \\
\hline 6.19 & Eucalyptol & 4.14 & 1.45 & 7.92 & 3.99 & 7.07 & 4.00 & 9.27 & 7.86 & 8.50 \\
\hline 6.27 & trans- $\beta$-Ocimene & - & 0.73 & 0.51 & 0.52 & - & 0.75 & 8.93 & 10.12 & 0.51 \\
\hline 6.47 & cis- $\beta$-Ocimene & 13.28 & 14.10 & 8.92 & 18.68 & 13.75 & 14.84 & - & - & 10.54 \\
\hline 6.66 & $\gamma$-Terpinene & 0.85 & 1.22 & 0.65 & 1.08 & 1.22 & 2.46 & 0.28 & 0.56 & 1.00 \\
\hline 7.20 & Terpinolene & 1.76 & 1.43 & 0.68 & 5.03 & 3.30 & 6.02 & 0.93 & 0.94 & 1.02 \\
\hline 7.64 & $\beta$-Linalool & 0.44 & 0.51 & 0.48 & 0.16 & 0.33 & 0.24 & 0.37 & 0.26 & 0.23 \\
\hline 8.34 & $\begin{array}{c}\text { 2,4,6-Octatriene, 2,6-dimethyl, } \\
\text { (E,Z) }\end{array}$ & 0.04 & 0.05 & - & 0.05 & 0.07 & 0.08 & 0.02 & 0.05 & - \\
\hline 9.06 & Terpinen-4-ol & 0.18 & 1.00 & 1.07 & 0.01 & 0.03 & 0.70 & 0.01 & 0.22 & 0.73 \\
\hline 9.50 & $\alpha$-Terpineol & 0.06 & 0.15 & 0.17 & 0.06 & 0.10 & 0.06 & 0.33 & 0.29 & 0.20 \\
\hline 9.71 & cis-4-Decenal & 0.02 & 0.03 & - & - & - & - & - & - & - \\
\hline 9.85 & Decanal & 0.01 & 0.003 & - & - & - & - & - & - & - \\
\hline 9.89 & Estragol & 0.01 & - & - & - & 0.03 & 2.04 & - & 0.33 & 0.10 \\
\hline
\end{tabular}




\begin{tabular}{|c|c|c|c|c|c|c|c|c|c|c|}
\hline 10.77 & $\beta$-Citral & 0.03 & - & - & - & - & - & - & 0.01 & - \\
\hline 11.21 & $\alpha$-Citral & 0.03 & - & - & - & - & - & 0.02 & - & - \\
\hline 11.40 & $\gamma$-Gurjunene & - & - & - & - & 0.0003 & - & - & - & - \\
\hline 11.43 & $\begin{array}{c}\text { Bicycle [5.2.0] 4-methylene-2, } \\
\text { 8, 8-trimethyl-2-vinil-nonano }\end{array}$ & 0.01 & 0.01 & 0.004 & 0.02 & - & - & 0.02 & 0.003 & - \\
\hline 11.55 & $\gamma$-Elemene & - & - & - & - & - & 0.02 & - & - & 0.01 \\
\hline 11.56 & Elixene & 0.03 & 0.03 & 0.02 & 0.08 & 0.05 & - & 0.06 & 0.02 & - \\
\hline 11.76 & $\alpha$-Cubebene & 0.06 & 0.05 & 0.05 & 0.14 & 0.08 & 0.03 & 0.11 & 0.04 & 0.02 \\
\hline 11.99 & Clovene & - & - & - & 0.01 & - & - & 0.01 & 0.003 & 0.004 \\
\hline 12.03 & Eugenol & 6.63 & 8.40 & 19.76 & - & 2.51 & 6.51 & - & - & - \\
\hline 12.20 & Copaene & 1.05 & 0.85 & 0.79 & 1.47 & 0.68 & 0.97 & 0.92 & 0.47 & - \\
\hline 12.36 & $\beta$-Bourbonene & - & - & 0.02 & - & - & 0.02 & - & - & - \\
\hline 12.46 & $\beta$-Elemene & 2.20 & 0.86 & 0.79 & 1.06 & - & 0.33 & 3.69 & 1.53 & 1.08 \\
\hline 12.73 & Eugenol methyl ether & 15.53 & 12.85 & 7.99 & 2.24 & 13.48 & 11.47 & 13.05 & 17.75 & 19.30 \\
\hline 13.03 & $\beta$-Caryophyllene & 23.29 & 21.90 & 18.04 & 27.71 & 19.46 & 15.63 & 29.09 & 18.25 & 17.00 \\
\hline 13.08 & $\begin{array}{c}\text { Bicycle [7.2.0] 10,10-dimethyl- } \\
\text { 2,6-bis (methylene)-, [1S- } \\
\left.\left(1 \mathrm{R}^{*}, 9 \mathrm{~S}^{*}\right)\right] \text { - undecane }\end{array}$ & 0.16 & 0.27 & 0.23 & 0.65 & 0.43 & 0.53 & - & 0.30 & 0.26 \\
\hline 13.24 & Aromadendrene & 0.04 & 0.03 & 0.03 & 0.15 & 0.08 & - & 0.13 & 0.04 & 0.03 \\
\hline 13.40 & Humulene-(v1) & 0.07 & 0.06 & 0.04 & 0.12 & 0.06 & 0.12 & 0.05 & 0.07 & 0.04 \\
\hline 13.48 & $\alpha$-Caryophyllene & 3.73 & 3.15 & 2.70 & 4.79 & 8.40 & 2.31 & 5.44 & 2.63 & 2.19 \\
\hline 13.58 & $\beta$-Cubebene & - & - & - & 0.09 & - & - & - & 0.02 & 0.04 \\
\hline 13.78 & $\gamma$-Muurolene & 0.20 & - & - & 0.38 & 0.22 & - & 0.32 & 0.13 & 0.23 \\
\hline 13.79 & $\begin{array}{c}\text { 2-Isopropenyl-4a, 8-dimethyl- } \\
1,2,3,4,4 \mathrm{a}, 5,6,7 \text {-octahydro } \\
\text { naphthalene }\end{array}$ & - & 0.16 & 0.09 & - & - & 0.14 & - & - & - \\
\hline 13.90 & Germacrene D & 0.56 & 0.30 & 0.24 & 1.34 & 1.36 & 0.24 & 1.09 & 0.36 & 0.23 \\
\hline 14.04 & $\beta$-Selinene & 0.22 & 0.27 & 0.23 & - & - & 0.11 & 0.31 & 0.13 & 0.34 \\
\hline 14.18 & $\alpha$-Selinene & 0.31 & 0.39 & 0.30 & - & - & 0.04 & 0.75 & 0.36 & 0.46 \\
\hline 14.28 & $\beta$-Cadinene & 0.003 & 0.003 & 0.02 & 0.03 & 0.02 & - & 0.02 & 0.01 & - \\
\hline 14.40 & $\gamma$-Cadinene & 0.14 & 0.10 & 0.07 & 0.31 & 0.17 & 0.08 & 0.24 & 0.09 & 0.06 \\
\hline 14.50 & $\delta$-Cadinene & 0.41 & 0.36 & 0.31 & 0.75 & 0.43 & 0.33 & 0.58 & 0.24 & 0.15 \\
\hline 14.71 & $\begin{array}{c}\text { 1, 2, 3, 4, 4a, 7-hexahydro-1, 6- } \\
\text { dimethyl-4-(1-methylethyl)- } \\
\text { naphthalene }\end{array}$ & 0.01 & 0.01 & 0.01 & 0.02 & 0.01 & 0.01 & 0.01 & 0.002 & 0.003 \\
\hline \multirow[t]{6}{*}{14.78} & $\alpha$-Amorphene & 0.04 & 0.03 & 0.03 & 0.10 & 0.06 & 0.02 & 0.08 & 0.03 & 0.02 \\
\hline & Oxylipins & 0.96 & 4.22 & 3.35 & 1.49 & 5.04 & 11.94 & 2.86 & 11.03 & 11.11 \\
\hline & Monoterpenes & 39.44 & 42.58 & 35.28 & 52.86 & 39.91 & 42.09 & 31.15 & 37.51 & 37.69 \\
\hline & Oxygenated monoterpenes & 4.88 & 3.11 & 9.63 & 4.21 & 7.54 & 5.01 & 10.00 & 8.64 & 9.66 \\
\hline & Sesquiterpenes & 32.55 & 28.84 & 23.99 & 39.19 & 31.50 & 20.93 & 42.93 & 24.74 & 22.15 \\
\hline & Phenylpropanoids & 22.17 & 21.25 & 27.75 & 2.24 & 16.01 & 20.02 & 13.05 & 18.08 & 19.40 \\
\hline
\end{tabular}

Forty-seven compounds were identified from leaves of female trees. From those, $\gamma$-cadinene and $\alpha$ amorphene showed significant differences $(P<0.05)$ and were more abundant in young leaves than in medium 
and mature leaves. Relative amounts of terpinen-4-ol were statistically higher in mature leaves than in the other leaves $(P<0.0001)$. In the case of male trees, forty-three compounds were identified from leaves. Fifteen of the nineteen sesquiterpene-type compounds identified were more abundant in young leaves than in the other leaves $(P<0.05)$. These compounds were: 1,2,3,4,4a,7-hexahydro-1,6-dimethyl-4-1-methylethyl-naphthalene; bicycle [5.2.0] 4-methylene-2,8,8-trimethyl-2-vinil-nonane; $\gamma$-cadinene; $\gamma$-murolene; $\alpha$-cubebene; copaene; germacrene $\mathrm{D} ; \delta$-cadinene; $\alpha$-amorphene; $\beta$-selinene; $\beta$-elemene; elixene; $\alpha$-caryophyllene; $\beta$-caryophyllene and aromadendrene. This suggests that sesquiterpenes biosynthesis in the young leaves of male trees probably had turnover activity that could be related to the tree phenology, specifically the ripening fruit period, as the female trees presented fructification but not the male trees.

\section{Groups of VOCs identified in the leaves from each type of tree}

Relative abundance of the distinct groups of VOCs was analyzed in the leaves from the different trees. Significant differences $(P<0.05)$ were only observed in male trees leaves, since sesquiterpenes had a higher relative amount in young leaves than in medium and mature leaves (Fig. 3).

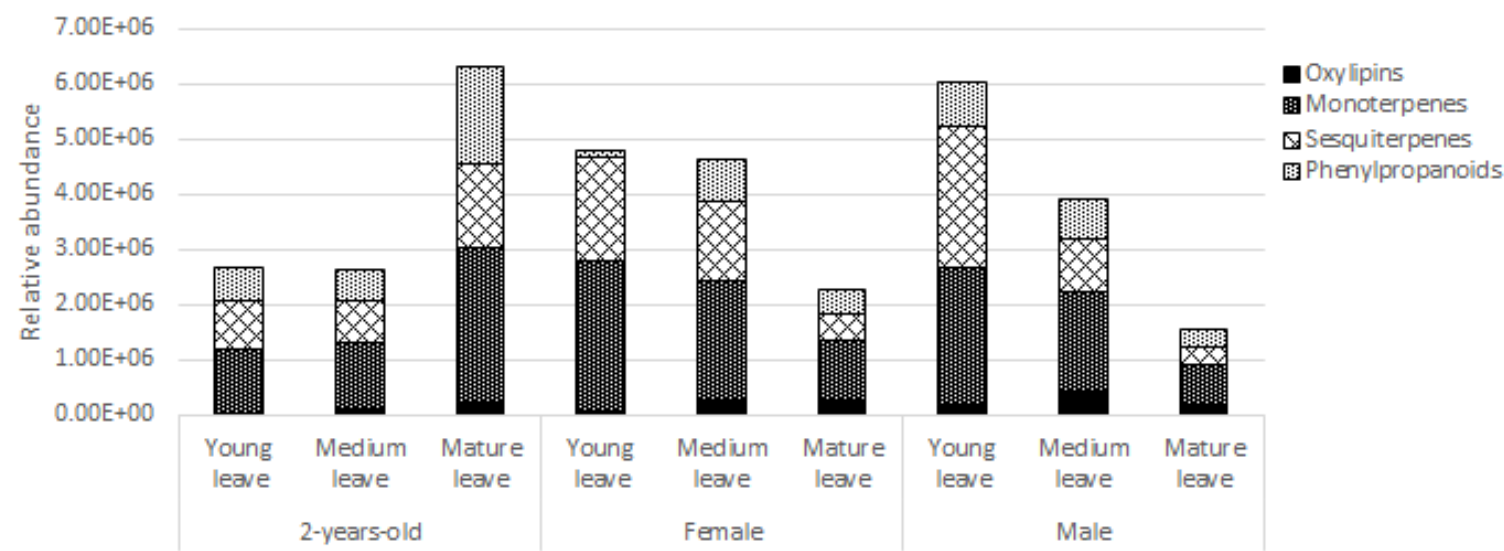

Fig. 3. Relative abundance of VOCs groups in leaves of Pimenta dioica at different developmental stages from 2 -years-old trees, as well as female and male trees of 14-years-old.

\section{Comparison of leaves from same developmental stage of different trees}

Because allspice fruit is used as an international spice, then it is of great interest to evaluate if the leaves from different development stages, can offer similar aroma and flavor. For this reason, we compared the VOCs identified in the same development stage between the different trees to elucidate if leaves can be used as material for essential oil extraction regardless of the tree type.

\section{Young leaves}

The VOCs $\gamma$-murolene, $\gamma$-cadinene, $\delta$-cadinene and $\alpha$-amorphene were detected in young leaves from all the tree types in the study with higher relative amount $(P<0.05)$ in 2-years-old trees than the others. Male trees showed high concentrations of eucalyptol and trans-2-hexenal compared with the other type of trees $(P<0.01)$. Terpinen-4-ol was present in all trees with 2 -years-old trees having higher relative abundance $(P<0.01)$. The oxylipins group presented significant differences $(P<0.05)$ in young leaves from male trees since they presented a higher relative amount than young leaves from 2-years-old and female trees. The relative amount of monoterpenes in young leaves was higher in female trees $(P<0.05)$ than in the other type of trees. 


\section{Medium leaves}

No significative differences of VOCs groups were detected among medium leaves of any type of tree in the study. trans- $\beta$-Ocimene was identified only in female and male trees, with higher relative amount in the male trees than the female trees $(P<0.05)$.

\section{Mature leaves}

Eucalyptol, $\beta$-pinene, $\beta$-linalool and $\alpha$-terpineol relative amounts were higher in mature leaves of 2years-old trees $(P<0.05)$ than mature leaves of female and male trees. Also, monoterpenes group presented a higher relative amount in mature leaves of 2-years-old trees than those of the other type of trees $(P<0.05)$.

Allspice essential oil is characterized for its composition: a richness of compounds that belongs to different groups of VOCs. Nevertheless, in the present study oxygenated sesquiterpenes were not detected probably due to the weather conditions or tree phenology. Neither Zini et al. [7] detected oxygenated sesquiterpenes in leaves of Eucalyptus species using SPME-GC-MS even when they detected spatulenol in the essential oil from the same samples, one of the most common oxygenated sesquiterpene compound in these species. The authors mention the low affinity of the fiber to polar compounds as the reason since the fiber composition was PDMS. In this study, a DVB/CAR/PDMS fiber was used, which is more effective for the capture of polar compounds. Interestingly, we were able to detected spatulenol, caryophyllene oxide and $\alpha$ cadinol in previous assays with $P$. dioica leaves. All of these compounds are oxygenated sesquiterpene that were not identified in the present study, probably due to the date of leaf collection.

\section{Comparison of female and male profile}

In the present study, the compounds identified in female and male trees were analyzed by PLS-DA (Partial Least Squares-Discriminant Analysis) to discern the differences between trees and to identify a discriminated model (Fig. 4). The first two components, which are denoted in the axes of Fig. 4, explain the $48.1 \%$ of variance. PLS-DA shows that the leaves from same developmental stage can be discriminated between female and male trees, thus VOCs of their leaves are different. However, the confidence region of male young leaves is overlapping with that of female medium leaves. A similar case is observed when comparing male medium leaves with female mature leaves. Contrary, there are regions which showed no overlapping, thus indicating compounds without differences between each type of tree.

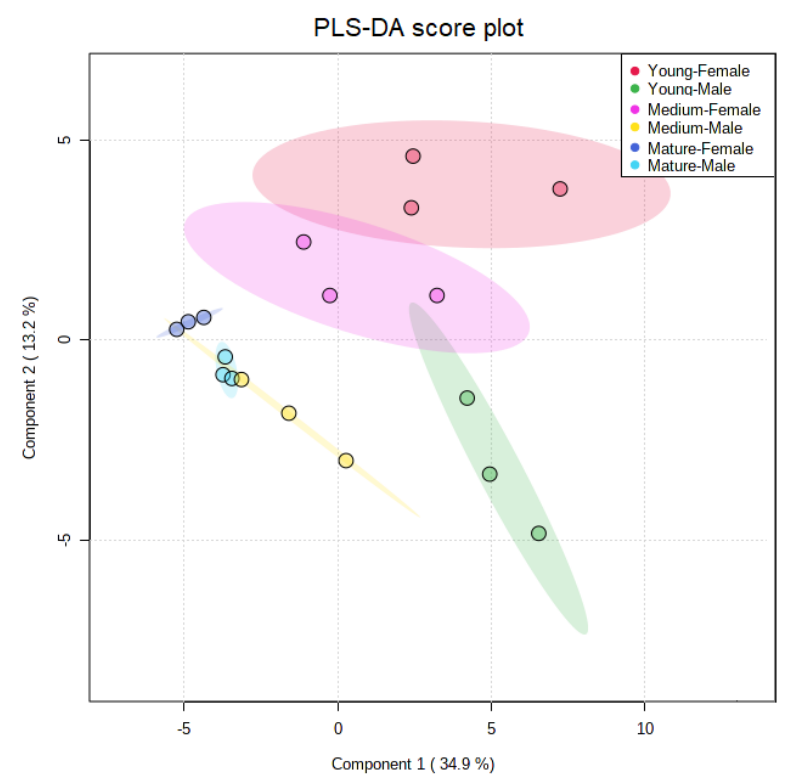

Fig. 4. Partial least squares discriminant analysis (PLS-DA) corresponding to VOCs identified in Pimenta dioica leaves at different developmental stages from female and male trees. 
A multivariate analysis was performed obtaining a heatmap to provide an overview of volatile profiles from female and male leaves at different developmental stage (Fig. 5). A higher relative amount of sesquiterpenes was observed in young leaves than medium and mature leaves from female and male trees. From the heatmap, the monoterpenes $\gamma$-terpinene and cis- $\beta$-ocimene, had a higher relative amount in leaves of female trees than leaves of male trees. Minott and Brown [8] observed that $\gamma$-terpinene was detected with a higher percent in female leaf oil $(P<0.005)$ than in male leaf oil.

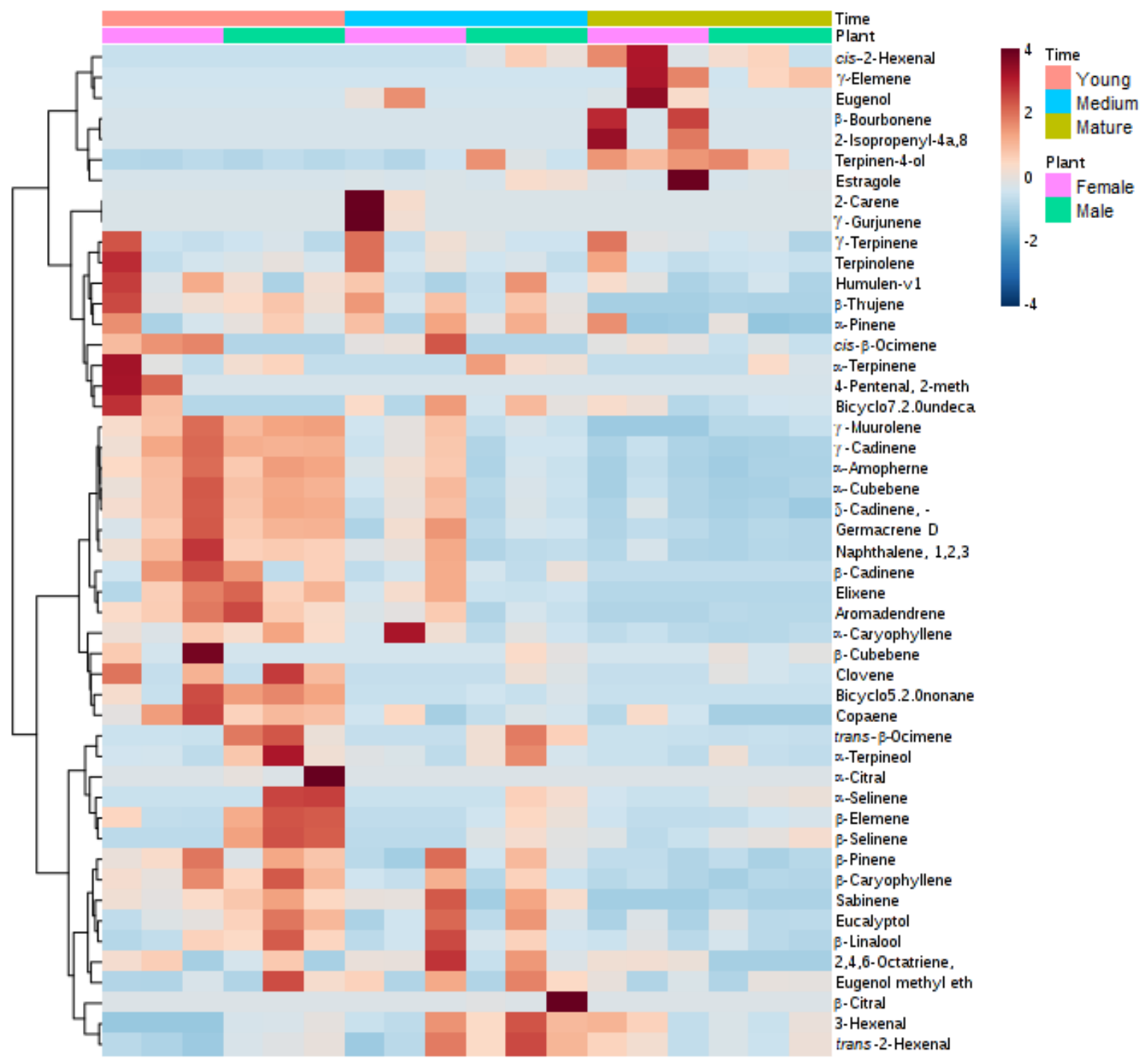

Fig. 5. Heatmap of the 49 compounds identified in leaves of Pimenta dioica at different developmental stages from female and male trees.

Compounds $\beta$-bourbonene; 2 -isopropenyl-4a, 8-dimethyl-1,2,3,4,4a,5,6,7-octahydronaphthalene; $\gamma$ gurjunene; 2-carene and 2-methyl-4-pentenal were detected exclusively in female trees, while $\alpha$-citral and $\beta$ citral were detected only in male trees. These compounds could be used as potential biomarkers for sex determination, though more analysis must be done to have an acceptable assurance. 
For the information above, it would be interesting to identify the potential biomarkers for the 2-yearsold tree profiles. Surprisingly, the possible biomarkers of female and male trees were both detected in two out of three undifferentiating trees. On the other hand, 2-isopropenyl-4a, 8-dimethyl-1,2,3,4,4a,5,6,7-octahydro naphthalene was detected in the third undifferentiating tree. This compound appears to be exclusive of female medium and mature leaves.

\section{VOCs profile from leaves of $\boldsymbol{P}$. dioica is comparable to the fruit essential oil profile}

In the present study, 18 of the 55 compounds identified were presented in all the samples. These compounds were: $\alpha$-pinene, $\beta$-pinene, eucalyptol, $\gamma$-terpinene, terpinolene, $\beta$-linalool, terpine- 4 -ol, $\alpha$-terpineol, $\alpha$-cubebene, $\beta$-caryophyllene, humulene-(v1), $\alpha$-caryophyllene, germacrene $\mathrm{D}, \gamma$-cadinene, $\delta$-cadinene, cubebene, $\alpha$-amorphene and eugenol methyl ether. These compounds showed a similar relative abundance in all developmental stages in the different trees and have been reported to be the main components of the essential oil from leaves and fruits of $P$. dioica. This indicate that the technique employed, SPME-GC-MS, is a useful method to analyze components in biological matrices as leaves, regardless the tree type and developmental stage to be used as material for essential oil extraction.

Nevertheless, eugenol was present in leaves from undifferentiated and female trees. This compound belonged to the three major compounds of the VOCs profiles of these trees, even when it is the main component in essential oil of $P$. dioica. In male trees, it was present only in one repetition probably due to climate factors or the time of collection. SPME-GC-MS is a valuable technique to study the compounds from a variety of matrices, however the profile obtain from this technique may be different from that when essential oil is examined by direct injection into the GC-MS. Bajer et al. [6] compared the profiles obtained by SPME-GC-MS and the essential oil obtained by hydrodistillation of allspice dried fruits. The results were not able to observe that eugenol was the principal compound even when is the major in the profile of dried fruit essential oils according to previous studies [2,5], nevertheless methyl eugenol was the major compound in allspice berries profile obtained by SPME and hydrodistillation. Although in the present study we were unable to observe eugenol in most leaves from male trees, different growth stage and other variants are necessary to analyze the presence of eugenol and evaluate the potential use of the essential oil in the industry.

It was not possible to detect eugenol in most of leaves from male trees, but eugenol methyl ether belonged to the three principal compounds detected. In the phenylpropanoid metabolic pathway, eugenol is the precursor of eugenol methyl ether, a compound identified in all the samples. For this reason, probably the absence of eugenol was because it is used as substrate by eugenol O-methyl transferase (EOMT) for the eugenol methyl ether biosynthesis [9].

\section{Conclusion}

SPME-GC-MS was a powerful technique to evaluate the VOCs profile from P. dioica leaves. Data provide a great diversity of VOCs regardless of the leaf and tree analyzed. Our results highlight the importance of the sites of biosynthesis in leaves that must be characterized in this species and analyze through the tree phenology to obtain a better outlook of $P$. dioica metabolism. In resume, in 2-years-old trees, mature leaves have a higher relative amounts of VOCs than medium and young leaves, even when these trees do not produce fruits, thus the leaves offer a potential economic use. On the other hand, relative amounts of VOCs in leaves for female and male trees trend to be lower with the leaf development. In this case, young and medium branches are pruned to maintain the height of the trees for the fruit harvest so they can be commercialized to obtain essential oil or to be used as condiment. In this manner, there could be a contribution to the regional development of the small producers and a preservation and motivation of the crop of this valuable tree species. Even $P$. dioica dried fruits are commercialized worldwide, the leaves offer an alternative for the market of spices. Both present similar VOCs and their major compounds are comparable. We consider that leaves, regardless of the tree type, offer a potential source of essential oil that could be used in a wide variety of applications, such as in cosmetics, food preservatives, perfumes and pharmaceuticals. 


\section{Acknowledgments}

IML acknowledges her CONACyT postgraduate scholarship.

\section{References}

1. Martínez, D.; Hernández, M.-A.; Martínez, E.-G. La pimienta gorda en México (Pimenta dioica L. Merrill): avances y retos en la gestión de la innovación. CIESTAAM. Universidad Autónoma Chapingo. 2013.

2. Krishnamoorthy, B.; Rema, J., in: Handbook of herbs and spices, Vol. 2, CRC, Woodhead Publishing, England, 2004, 113-135.

3. Chapman, G. P. Ann. Bot. 1964, 28, 451-458

4. Rao, P.S.; Navinchandra, S.; Jayaveera, KN. Int. Curr. Pharm. J. 2012, 1, 221-225.

5. Ravindran, P. N. The Encyclopedia of Herbs \& Spices. Vol. I. CABI. USA. 2016. 25-28

6. Bajer, T.; Ligor, M.; Ligor, T.; Buszewski1, B. J. Sep. Sci. 2016, 39, 769-775. DOI: 10.1002/jssc.201500605

7. Zini, C.; Zanin, K. D.; Christensen, E.; Caramao, E. B.; Pawliszyn, J. J. Agric. Food Chem. 2003, 51, 2679-2686.

8. Minott, A. D.; Brown, A. A. J. Essent. Oil Res. 2007, 19:354-357. DOI: 10.1080/10412905.2007.9699303

9. Gang, D.R.; Wang, J.; Dudareva, N.; Hee N., K.; Simon, E. J.; Lewinsohn, E.; Pichersky, E. Plant Physiol. 2001, 125, 539-555. 